\title{
INTEGRAÇÃO DE SISTEMAS COMPUTACIONAIS E MODELOS LOGÍSTICOS DE OTIMIZAÇÃO PARA PREVENÇÃO E COMBATE À DENGUE
}

\author{
Marcos José Negreiros * \\ Airton Fontenele Sampaio Xavier \\ José Wellington de Oliveira Lima \\ Universidade Estadual do Ceará (UECE) \\ Fortaleza-CE, Brazil \\ negreiro@graphvs.com.br, axavier@secrel.com.br,
} jlima@,fortalnet.com.br

\author{
Adilson Elias Xavier \\ Nelson Maculan \\ Universidade Federal do Rio de Janeiro (UFRJ) \\ Rio de Janeiro - RJ, Brazil \\ adilson@cos.ufrj.br, maculan@cos.ufrj.br
}

\section{Philippe Michelon}

Université d'Avignon et des Pays de Vaucluse (UAPV)

Avignon Cedex 9, France

philippe.michelon@lia.univ-avignon.fr

* Corresponding author / autor para quem as correspondências devem ser encaminhadas

Recebido em 12/2005; aceito em 01/2008 após 1 revisão

Received December 2005; accepted January 2008 after one revision

\section{Resumo}

O uso do conhecimento da ciência moderna no sentido de aprimorar os esforços de combate a doenças transmitidas por animais, denominadas zoonoses, em regiões tropicais é uma preocupação considerada de grande relevância pelos gestores da OMS. Este trabalho apresenta o desenvolvimento de uma metodologia de planejamento logístico para prevenção e combate à dengue, baseada em sistemas Geográficos de Informação e sistemas de Apoio a Decisão com modelos incorporados de otimização. Apresentamos também, uma ferramenta computacional, baseada na Web, desktops e palms e poquets, capaz de aplicar tal metodologia. Estudos e testes piloto, nas cidades de Sobral e Fortaleza, Ceará foram realizados. Os resultados dessa aplicação computacional forneceram, após os testes, uma melhor visualização da dimensão do problema de coordenação do combate para os gestores da dengue, ou seja, foram plenamente exitosos nesses experimentos pioneiros.

Palavras-chave: logística de combate a doenças tropicais; programação inteira; SADE; sistemas para Web.

\begin{abstract}
The use of modern science knowledge towards improving the efforts to combat zoonoses -, diseases that are communicable by animals -, in tropical regions is a concern taken into account by the World Health Organization (WHO) officials. In this article we intend to present the development of a logistical planning methodology for the prevention and combat of dengue, based on Geographic Information Systems (GIS) and Decision Support Systems with optimization models incorporated. We also present a Web, desktop, palm and pocket-based computational framework tool for use as a support in the application of such methodology, which was tested in a pilot case in the city of Sobral and most recently in the city of Fortaleza, state of Ceará, Brazil, and that has been providing a better view of the dimension of the problems faced by the officials responsible for coordinating the combat of diseases caused by zoonoses, namely dengue.
\end{abstract}

Keywords: logistics for the combat of tropical diseases; integer programming; spatial DSS; Web systems. 


\section{Introdução}

O objetivo deste trabalho é contemplar o uso de técnicas de pesquisa operacional na organização e no equacionamento das operações logísticas de combate à dengue, em uma cidade brasileira de porte médio, Sobral, e de grande porte Fortaleza, localizadas no Estado do Ceará.

Considerando, outrossim, que as atividades de combate à dengue são similares às usadas para combater outras zoonoses, temos a expectativa de que essa metodologia tenha um escopo bem maior, quer para doenças similares a dengue, quer para outros países com desenvolvimento econômico-social similar ao Brasil.

Neste trabalho, relacionamos a utilização de um conjunto compacto de técnicas de pesquisa operacional, que foram testadas para atuar no planejamento e na execução de atividades de combate e de controle da dengue. Um complexo sistema de informações foi projetado e desenvolvido com o objetivo de agilizar a disposição de informações provenientes do campo, sobre a dinâmica espacial-temporal da doença; e conseqüentemente facilitar a tomada de decisão dos gestores de saúde em tempo hábil.

Muitas dessas técnicas são amplamente registradas na literatura, bem como têm sido regularmente utilizadas em aplicações associadas a diferentes setores da economia. O caráter inovador do presente trabalho é a articulação dessas técnicas no equacionamento e na resolução de um problema de saúde pública, portanto, aplicação de rara importância sócioeconômica em um setor em que o uso desses instrumentos não tem merecido uma maior atenção, de forma geral, em países em desenvolvimento.

O trabalho está organizado na seguinte ordem. Na seção 2, é apresentada uma descrição das características da doença dengue, dos procedimentos padrão de controle e de sua presença no mundo, em geral, e no Brasil, em particular. Na seção 3, é apresentado o esquema operacional adotado nas cidades de Sobral e em Fortaleza. Paralelamente, é feita a descrição inicial do sistema de informações proposto para suportar essas informações, basicamente, fundamentado em geoprocessamento combinado a sistemas de banco de dados para a Web e a aquisição de dados remotos. Na seção 4, são apresentados o planejamento de serviços dos agentes sanitaristas e dos veículos de prevenção e combate à dengue, bem como, de algumas formulações de modelos de programação matemática e de suas respectivas contrapartes no sistema de informações. Finalmente, na seção 5, são apresentadas as conclusões preliminares.

\section{Generalidades sobre a Dengue}

As rápidas mudanças demográficas, resultantes da migração não planejada das regiões rurais para as urbanas e do aumento da população nas áreas urbanas de pouca infra-estrutura, conduzem a uma maior incidência na transmissão de doenças e à difusão de patologias em áreas ainda não afetadas. No entanto, com relação ao surgimento de doenças transmitidas por mosquitos, mesmo uma população que esteja em área de risco pode registrar índices de infecção baixos, caso sejam adotadas medidas preventivas, tais como: operações tapa-valas, colocação de telas em cisternas e caixas d'água, uso de repelentes e, sempre que possível, campanhas educativas e de vacinação.

Em termos de morbidade e mortalidade, considera-se a febre de dengue, a febre de dengue hemorrágica (FDH) e a síndrome de choque por dengue (SCD) como as doenças virais mais importantes transmitidas por artrópodes: Aedes aegypti e Aedes albopictus. 
O impacto global da dengue tem aumentado de forma dramática nas últimas décadas, e ela é hoje classificada como uma doença infecciosa que emerge e re-emerge. A febre de dengue e a febre de dengue hemorrágica (FDH) acontecem hoje em mais de 100 países, com mais de 2,5 bilhões de pessoas em risco anualmente, e é estimado que haja 20 milhões de casos de infecção de dengue, resultando em aproximadamente 24 mil mortes. A OMS considera que é necessário um esforço coordenado global para trazer os recursos da ciência moderna no sentido de facilitar o controle das dez maiores doenças tropicais do mundo, [TDR, 2004].

No Brasil, existem referências à dengue desde 1849, quando teria ocorrido uma epidemia no Rio de Janeiro. Após ser considerado erradicado do Brasil em 1958, o Aedes aegypti foi novamente detectado e vem se desenvolvendo ao longo dos últimos 12 anos, de forma intensa e preocupante.

O combate ao mosquito deve ser feito de duas maneiras: eliminando os mosquitos adultos e, principalmente, acabando com os criadouros de larvas. Para isso, é importante descartar recipientes que possam acumular água ou protegê-los com tampas. Quaisquer recipientes com água e sem tampa, inclusive caixas d'água, podem vir a ser criadouros dos mosquitos que transmitem dengue. Recentes pesquisas (em Sobral e Fortaleza) de combate com peixes ornamentais (Peixe Beta, Betta Splendens e Tricogaster, Trichogaster trichopterus) demonstraram bons resultados, uma vez que tais peixes de água doce incorporam a larva e o mosquito na sua cadeia alimentar.

Uma medida para reduzir a população do mosquito adulto, é aplicar inseticida, utilizando-se o veículo "fumacê", que só deve ser empregado em caso de epidemia ou endemias localizadas nas zonas urbanas. $\mathrm{O}$ "fumacê", além de não acabar com os criadouros, precisa ser aplicado repetidas vezes - procedimento indesejável - a fim de matar os mosquitos que vão se formando. Por isso, é importante eliminar os criadouros do mosquito transmissor. Além da dengue, se estará também evitando que a febre amarela, que não ocorre nas cidades brasileiras desde 1942, volte a ser transmitida.

\section{ARCABOUÇO Computacional para a Gestão da Dengue}

O controle da dengue exige o gerenciamento de um volume imenso de informações sobre a existência de possíveis criadouros, sobre a presença do vetor nos diferentes criadouros domiciliares, ocorrência de casos humanos, realização de intervenções sobre as formas larvárias e adultas do vetor e intervenções educativas para redução e eliminação de criadouros. Essas informações mudam no tempo e no espaço. Por inacreditável que seja, na prática, a tomada de decisão sobre quando e onde intervir é baseada em sistemas informatizados com tecnologias de bancos de dados anacrônicas e planilhas gráficas, que levam em conta uma pequena parte das informações relevantes.

Nas cidades de Sobral e Fortaleza, no Ceará, o trabalho de combate à dengue envolve as informações obtidas pelas equipes de agentes sanitaristas sobre focos de vetores catalogadas diariamente, após a visita em média de 18 a 22 imóveis por agente. Uma vez as fichas preenchidas, os dados são entregues aos escritórios centrais, cujos funcionários devem digitar o grande volume de informações diárias. O trabalho se acumula de tal sorte que muitas vezes é impossível manter os registros fiéis da localização (imóvel a imóvel) dos principais focos, pelas quadras e bairros da cidade.

O problema de disponibilizar aos médicos, que recebem pacientes com dengue após constatação sorológica ou diagnóstico primário, mecanismos para que informem a

Pesquisa Operacional, v.28, n.1, p.1-27, Janeiro a Abril de 2008 
localização dos casos (residência e/ou local de trabalho) também é de natureza bastante difícil de ser tratado atualmente pelos órgãos gestores da saúde pública.

Por fim, diante das dificuldades da precisão da informação sobre os focos, trabalhos estatísticos de identificação dos principais focos e casos de forma a cruzá-los, também são muito empíricos dificultando a análise para o combate, e aumentando sobremaneira os custos operacionais envolvidos na questão da dengue e de outras doenças de mesma natureza sistêmica.

Após seis anos desenvolvendo trabalhos ligados direta e indiretamente a logística de distribuição, foi possível conseguir dominar as tecnologias da informação adequadas, combinando geoprocessamento, sistemas de apoio a decisão, sistemas de bancos de dados para Web e aquisição de dados remotos (ESRI-ARC-IMS, ESRI-MAPObjects, MS-SQL Server, Superwaba, Java).

A aquisição da informação diretamente no campo tornou-se fundamental, via palmtops ou poquets PC (Hand-Helds). Os formulários de campo dos agentes sanitaristas são transcritos para a internet via sistemas móveis. Um gerenciador dos bancos trata as informações pertinentes, as quais são imediatamente publicadas na rede, de modo que os gestores podem acompanhar a expansão dos focos e casos, numa visão dinâmica de evolução no tempo.

Os testes com o uso dessa tecnologia foram conduzidos na Regional II de Fortaleza/CE, com apoio da CVS/PMF, para o controle de Pontos Sentinela (pontos de controle quinzenal: borracharias, prédios em construção, ferro velhos, cemitérios, etc.), tendo atingido excelente resultado, com “dengue zero" em 20 dos 21 bairros da Regional II de Fortaleza.

A Figura 1 apresenta o sistema Webdengue exibindo os focos nas quadras de Sobral/CE e fazendo o cruzamento entre as informações de posicionamento dos focos e casos de dengue, na Regional II de Fortaleza/CE.

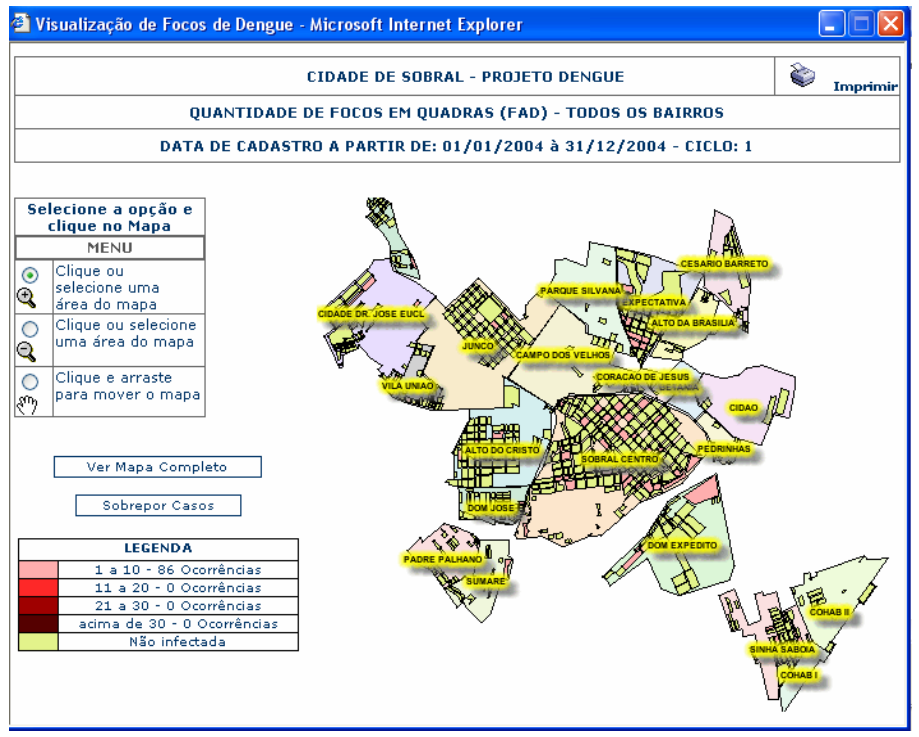

Figura 1(a) - Cidade de Sobral, Ceará. 


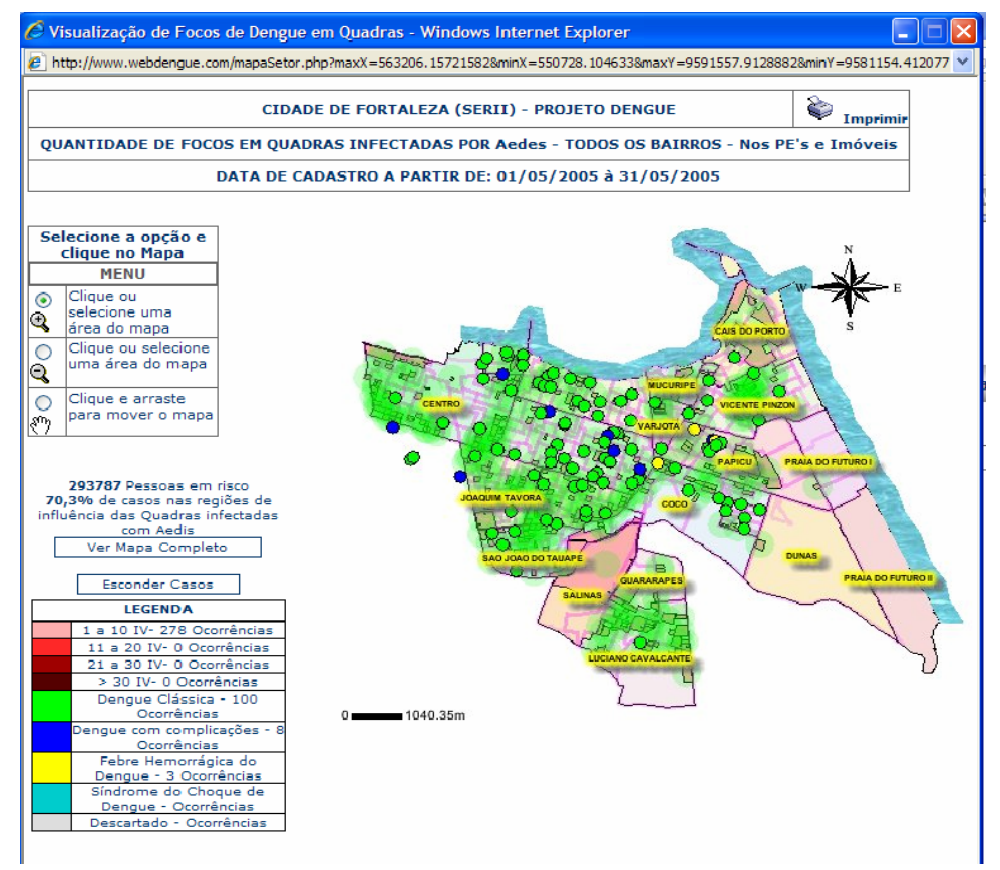

Figura 1(b) - Regional II de Fortaleza/CE.

Figura 1 - Visualização das áreas de aplicação dos testes com o framework.

O arcabouço (framework) é, pois, composto por um conjunto de cinco sistemas computacionais, Sistema Webdengue, sistema Gestor, sistema GeoGRAPHVS, e sistemas "Hand-Held" Agente e Supervisor, que conversam entre si no sentido de proporcionar ao gestor ou pesquisador, os recursos necessários para a tomada da decisão sobre "o quê fazer" quando do quadro endêmico ou epidêmico de doenças provocadas por zoonoses (Dengue, Febre Amarela, Malária e outras).

A Figura 2 apresenta uma visão resumida da integração das ferramentas, onde se tem atrelado ao sistema Webdengue o sistema Gestor, e as informações provenientes dos laboratórios de análises de focos (nos centros de zoonoses) e de casos humanos (LACEN). Os sistemas hand-helds se comunicam diretamente com o sistema Gestor e entre si, recebendo os dados do serviço e enviando os dados coletados ao sistema Gestor. O sistema Gestor contém um conjunto de plataformas de otimização, operando então como um Sistema de Apoio a Decisão Espacial (SADE), na construção das áreas de cobertura dos agentes, fazendo a escala de serviço e as rotas, e visualizando os dados de casos e focos. Por fim, o sistema GeoGRAPHVS faz a edição dos mapas urbanos, georeferenciando as informações de bairros, quadras, faces de quadra, imóveis, malha viária e hidrografia, podendo produzir mapas em produção paralela com composição em um servidor. Os mapas nele gerados, são transferidos para o sistema Gestor, que permite ao Webdengue visualizar todo o banco de dados numa perspectiva espaço-temporal, e fazer as visualizações de estatísticas pertinentes à notificação dos casos humanos, focos, pluviometria e acompanhamento de serviço dos agentes sanitaristas. 
O sistema tem a função precípua de aumentar a velocidade da coleta da informação sobre a evolução da doença através dos casos humanos, e cruzá-la à presença dos focos num determinado período de tempo (Webdengue), recebendo informações do pessoal da saúde envolvido com a notificação de casos, e do pessoal da zoonose com a notificação dos focos. Em geral, como é feito normalmente nas cidades brasileiras, isto leva de 15 a 30 dias, podendo chegar a muito mais; com o Webdengue isto acontece em segundos.

Uma vez integrados, os sistemas podem apresentar rapidamente para os gestores o quadro da evolução da doença, assim como auxiliam na análise de outros aspectos que não estão relacionados diretamente a ela. Mais importante é que os sistemas nacionais de informações (SINAN, Sistema Nacional para Acompanhamento dos Casos de Dengue e outras doenças e FAD, Sistema Nacional para Acompanhamento dos Focos de Febre Amarela e Dengue), são alimentados automaticamente pelo framework. Diferentemente do que é feito, aqui não se perde mais a informação do local exato, período e dia da presença do mosquito Aedes aegypti.

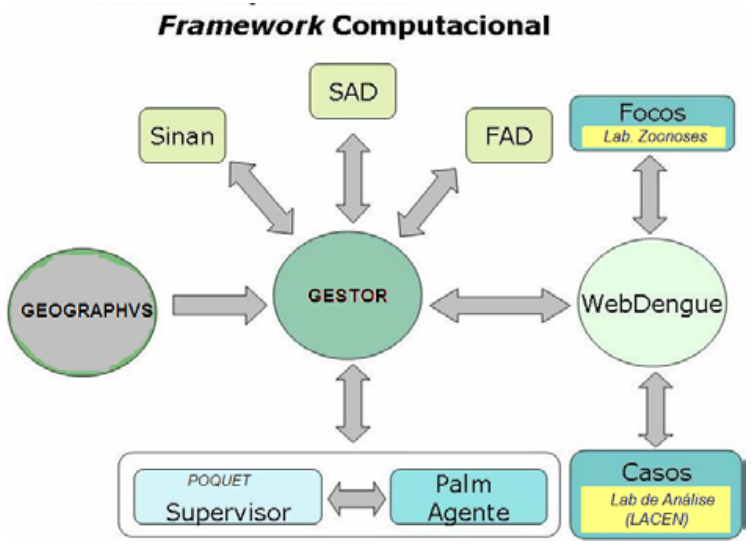

Figura 2 - Visão geral resumida do Framework.

A informação poderá estar disponível na velocidade e precisão necessárias, agora possivelmente após o dia de trabalho de cada agente ou tão logo o médico notifique o caso humano por ele observado.

Modelos estatísticos de acompanhamento climático, previsão de ocorrência de casos devido a mudanças climáticas, aglomerados dinâmicos (de focos de Aedes e casos humanos), assim como modelos de contágio, podem ser desenvolvidos para melhor estimar as influências expansionistas e indicar os inibidores para o avanço epidêmico, em um processo de apoio à tomada de decisão. Essas ferramentas são úteis aos gestores no momento que não apenas estarão ocupadas com a visão contextual e temporal da expansão da doença.

\section{Planejamento Logístico da Prevenção e Combate à Dengue}

A forma como se estabelece sua logística de prevenção e combate à dengue, caracteriza-se pela atuação constante em larga escala de agentes sanitaristas e, em situações epidêmicas, a atuação de veículos nas regiões infectadas pelo mosquito. 
A experiência prática mostra que a grande parcela do custo operacional do processo cabe às tarefas executadas pelos agentes sanitaristas, que, por sua vez, ensejam a maior efetividade nos trabalhos de prevenção e combate. Duas abordagens existem no controle, Focal e Pontos Sentinela (PS's). Na atividade de controle focal turmas de agentes são formadas para atuar em determinada área, e durante o ciclo de visita, em geral 35-45 dias úteis (3-4 meses, ciclo), em que toda a cidade deve ser coberta, imóvel a imóvel. Já na atividade de controle de PS's (Pontos Sentinela: borracharias, ferros-velhos, restaurantes, prédios em construção), o número de visitas diário varia em função do tamanho do imóvel e do montante de trabalho. Nesse último, o ciclo é bem mais rápido, dura 14 a 15 dias. A divisão do trabalho entre agentes para as duas modalidades tem sido feita de forma superficial, apesar dos centros de zoonoses possuírem o cadastro de todas as quadras e locais de difícil acesso em mapas manuais.

Os indicadores de cobertura dos imóveis são relevantes para as equipes, e pendências (imóveis não visitados por estar fechado ou devido ao ocupante não ter permitido a visita do agente por uma razão qualquer) têm que ser cobertas no ciclo, haja vista esse ser o maior indicador sobre a qualidade do trabalho no período.

O trabalho dos veículos "fumacês", pode ser amplamente melhorado, de fato, seja pela confecção dos percursos, seja pela criação de áreas de atendimento conforme os setores de risco, seja pela minimização do esforço empreendido no atendimento aos percursos do veículo, considerando sua periodicidade de trabalho.

Assim, os modelos logísticos utilizados podem ser considerados resumidamente como segue:

1. Modelos de Distritamento (Districting Models), [BLL 2003]

1.1. Áreas de cobertura das equipes de agentes sanitaristas: visam à construção de regiões compactas que permitem a cobertura de uma equipe no tempo do ciclo (macro-região, ou bairro, para o caso de grandes cidades);

1.2. Áreas de cobertura de agentes sanitaristas: dentro das regiões compactas construídas pelo modelo anterior, definição de áreas menores compactas de cobertura de um grupo menor de agentes ou um único agente, onde os agentes devem estar afastados entre si ao longo do período de modo a permitir uma boa amostragem diária do quê está acontecendo na cidade;

1.3. Áreas de cobertura dos veículos "fumacês" nas situações epidêmicas: seguindo basicamente o raciocínio dos modelos anteriores, porém considerando-se uma malha viária, e não uma cobertura baseada no número de imóveis.

\section{Modelos de Escala de Agentes e Veículos "Fumacês"}

Buscam definir a divisão de cobertura das equipes de veículos e/ou agentes nas diversas áreas, conforme suas prioridades e dificuldades inerentes.

3. Modelos de Roteamento de Veículos

3.1. Modelos de percurso de agentes: definição do percurso do agente sanitarista no seu ciclo de trabalho, considerando que seu trabalho, quadra a quadra, ou imóvel a imóvel, deve evoluir conforme definido pelo modelo em 1.2.

3.2. Modelos de percurso do "fumacê": definição do percurso considerando uma topologia específica na rede (viagem pelos lados da rua), e quantidade máxima de inseticida a ser pulverizado no ar por trajeto.

Pesquisa Operacional, v.28, n.1, p.1-27, Janeiro a Abril de 2008 
O trabalho dos agentes é a preocupação preliminar. Escalá-los e distribuí-los entre os imóveis é uma tarefa árdua para o supervisor do centro, tanto de Fortaleza quanto Sobral. Assim, são apresentados dois modelos pertinentes a distribuição da carga de serviço diária do agente sanitarista. São também considerados dois modelos relativos à escala do veículo "fumacê" e seu percurso nas áreas de atendimento.

A Figura 3, de uma forma simplificada, apresenta uma visão esquemática do relacionamento entre os modelos acima. Os modelos de distritamento de agentes e veículos são preliminares na definição de atuação dos mesmos contemplando a distribuição espacial. Em seguida, temos a etapa de escala de agentes e veículos, contemplando a distribuição temporal. Por fim, temos a fase de roteamento de agentes, visando o controle focal e de pontos sentinela, e de roteamento de veículos, combate ao mosquito.

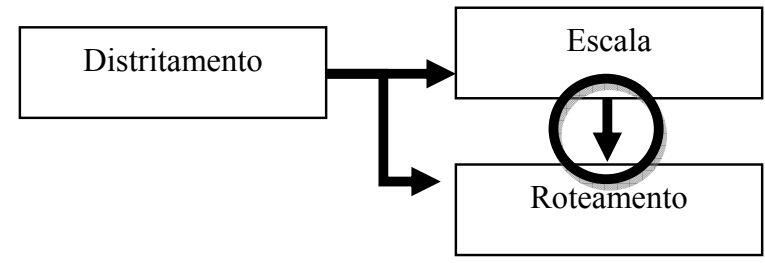

Figura 3 - Diagrama de relacionamento entre os modelos logísticos.

\subsection{O Planejamento da Cobertura de Agentes Sanitaristas (Modelos de Distritamento)}

O planejamento das tarefas de cobertura dos agentes sanitaristas pode ser efetuado através de modelos de agrupamento estendidos, conforme se pode ver na literatura de distritamento pertinente, [GN 1970], [BLR 1981], [MJN 1998], [BEL 2003], [BLL 2003], [ZHD 2007].

O problema geral de agrupamento pode ser tratado do seguinte modo:

Seja $S$ o conjunto de imóveis a serem visitados, onde $s_{\mathrm{j}}$ define as coordenadas espaciais do imóvel $j$, ou seja:

$$
S=\left\{s_{1}, \ldots, s_{m}\right\}, \text { onde } s_{\mathrm{j}} \in \mathfrak{R}^{2}, j=1, \ldots, m .
$$

O objetivo desse primeiro modelo é o particionamento do conjunto $S$ em $q$ subconjuntos disjuntos $S_{i}, \mathrm{i}=1, \ldots, q$, conforme [1], de modo a subsidiar as operações de planejamento e de controle das atividades de combate à dengue,

$$
S=\bigcup_{i=1}^{q} S_{i}, \quad S_{i} \bigcap S_{k}=\varnothing, \quad i=1, \ldots, q ; \quad k \neq i
$$

Trata-se, assim, de um clássico problema de agrupamento, tratado pela bibliografia em diversas publicações, por exemplo, [HART75], [SPATH85], [KR90] e mais recentemente [EL 2001], [TK 2003].

Cada subconjunto $S_{i}$ pode ser representado por seu centróide [2],

$$
x_{i}=\frac{1}{\left|S_{i}\right|} \sum_{j \in S_{i}} s_{j}
$$

onde $\left|S_{i}\right|$ é a cardinalidade do subconjunto $S_{i}, i=1, \ldots, q$. 
A formulação mais tradicional do problema de agrupamento pode ser colocada sob a forma do seguinte problema de otimização:

$$
\text { (Min-Sum Clustering) Minimizar } \sum_{i=1}^{q} \sum_{j \in S_{i}}\left\|s_{j}-x_{i}\right\|^{2}
$$

$$
\text { tal que } X=\left\{x_{1}, \ldots, x_{q}\right\} \text { e } x_{i} \in \mathfrak{R}^{2}, i=1, \ldots, q .
$$

O problema (Min-Sum Clustering) acima, conhecido como o de agrupamento segundo o critério de mínima soma de quadrados, pode ser colocado na seguinte forma equivalente [4]:

$$
\underset{\mathrm{X}}{\operatorname{Minimizar}} \sum_{i=1}^{m} d_{j}^{2}(X)
$$

onde,

$$
d_{j}(X)=\min _{i}\left\|s_{j}-x_{i}\right\|
$$

Trata-se assim de um problema não-linear, com um conjunto de restrições fortemente nãodiferenciáveis. A não diferenciabilidade surge pelo fato de que a distância $d_{j}(X)$ associada a cada observação $s_{\mathrm{j}}$ ser definida pelo centróide mais próximo, sendo assim seu valor é determinado por componentes diferentes do vetor $X \in \mathfrak{R}^{2 q}$, em diferentes regiões desse espaço.

O problema acima foi abordado através do método de suavização hiperbólica, que transforma o modelo [4] em uma seqüência de problemas completamente diferenciáveis. Foram obtidas soluções de alta qualidade para agrupamentos testados sobre os centros de quadra da cidade de Sobral. A Figura 4 apresenta um resultado de agrupamento de 13280 centros de quadra da cidade de Sobral divididos em 11 grupos distintos, [XNMM05].

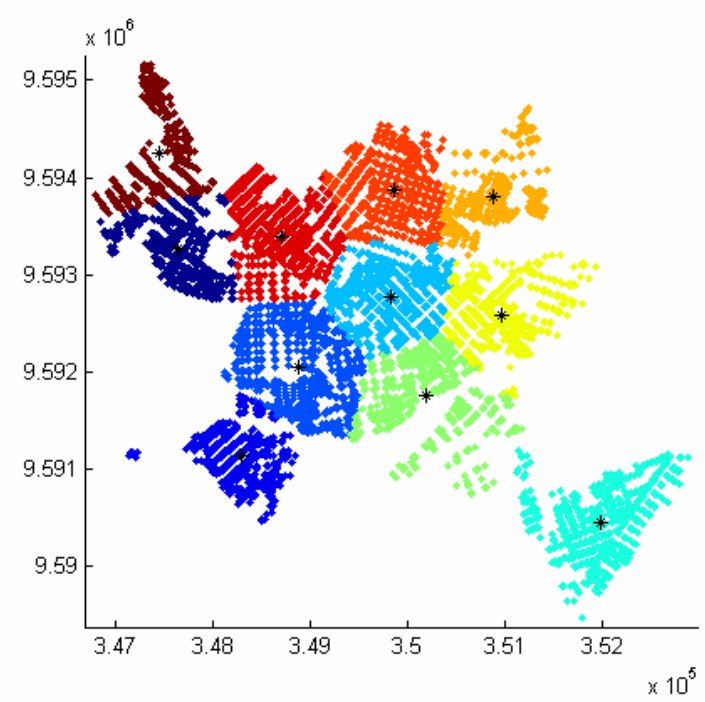

Figura 4 - Resultado do agrupamento de 13260 centros de quadras, para a cidade de Sobral/CE, após a utilização do método de clustering com suavização hiperbólica. 
Outros métodos de agrupamento existem, entre exatos e heurísticos, destacam-se os heurísticos como Forgy, $k$-Means, $j$-Means, $c$-Means e variações, [HM 2001], [TK 2003], [NP 2006]. A Tabela 1 abaixo mostra os resultados obtidos pela nova metodologia desenvolvida usando suavização hiperbólica e aqueles pelo algoritmo $j$-Means para diferentes quantidades de grupos $(\mathrm{q}=8, . ., 11)$, onde os pontos representam as quadras de Sobral. Esses resultados exibem claramente a eficiência e a robustez da proposta. Nessa tabela, temos que:

$f_{H S C}$ é o valor da função objetivo da solução via suavização hiperbólica;

$f_{j \text {-means }}$ é o valor da função objetivo da solução via método $j$-means;

Tempo $_{H S C}$ é o tempo (em segundos) obtido pelo método de suavização hiperbólica;

Tempo $_{\text {-means }}$ é o tempo (em segundos) obtido pelo método $j$-means;

$E=\frac{100\left(f_{H S C}-f_{j-\text { means }}\right)}{f_{j-\text { means }}}$ é uma medida de comparação entre os dois métodos;

$R=\frac{\text { Tempo }_{H S C}}{\text { Tempo }_{j-\text { means }}}$ é o tempo computacional do método hiperbólico em relação ao método de $j$-means [HM 2001].

Tabela 1 - Resultados para a cidade de Sobral/CE: 8 a 11 agrupamentos.

\begin{tabular}{|c|c|r|c|r|r|c|}
\hline$q$ & $f_{\text {HSC }}$ & Tempo $_{\text {HSC }}(\mathrm{s})$ & $f_{j-\text { means }}$ & Tempo $_{j \text {-means }}(\mathrm{s})$ & $E$ & $R$ \\
\hline 8 & $0.40663 \times 10^{10}$ & 95.55 & $0.40674 \times 10^{10}$ & 2220.61 & -0.03 & 0.0430 \\
\hline 9 & $0.35783 \times 10^{10}$ & 78.11 & $0.38988 \times 10^{10}$ & 18.08 & -8.22 & 4.3202 \\
\hline 10 & $0.31477 \times 10^{10}$ & 127.89 & $0.56343 \times 10^{10}$ & 2259.02 & -44.13 & 0.0566 \\
\hline 11 & $0.27637 \times 10^{10}$ & 107.08 & $0.27637 \times 10^{10}$ & 26142.94 & 0.00 & 0.0041 \\
\hline
\end{tabular}

\subsubsection{Divisão da cidade entre turmas de agentes com restrições de capacidade}

Dentre os problemas existentes ligados diretamente ao planejamento da cobertura dos agentes sanitaristas, dois são diretamente extraídos de resoluções de problemas de clustering irrestrito, porém estendendo o conceito e incluindo restrições de capacidade (número máximo de imóveis a visitar num ciclo).

Assim, essa divisão deve ser feita de tal modo que cada partição seja coberta pela mesma turma ao longo do ciclo de visita. Aqui, temos um problema de clustering restrito, que conforme Negreiros \& Palhano ([NP2006]) pode ser resolvido através do Problema de Agrupamento Capacitado em Centro Geométrico.

Para o caso do serviço de controle focal, a divisão do trabalho entre os agentes é feita em função da quantidade de imóveis por agente por ciclo, e considerando também um limite inferior e superior de atendimento da área. Limites de 18 a 22 imóveis por dia por agente, turmas de 4 agentes, e um calendário com 42 dias úteis no ciclo, por exemplo, significariam, então, regiões com 3024 a 3696 imóveis para esse ciclo. 
A Figura 5 mostra uma visualização de uma solução do problema, o processo de divisão das áreas de cobertura dos agentes usando a técnica proposta por Negreiros \& Palhano ([NP2006]), incorporada ao sistema Gestor.

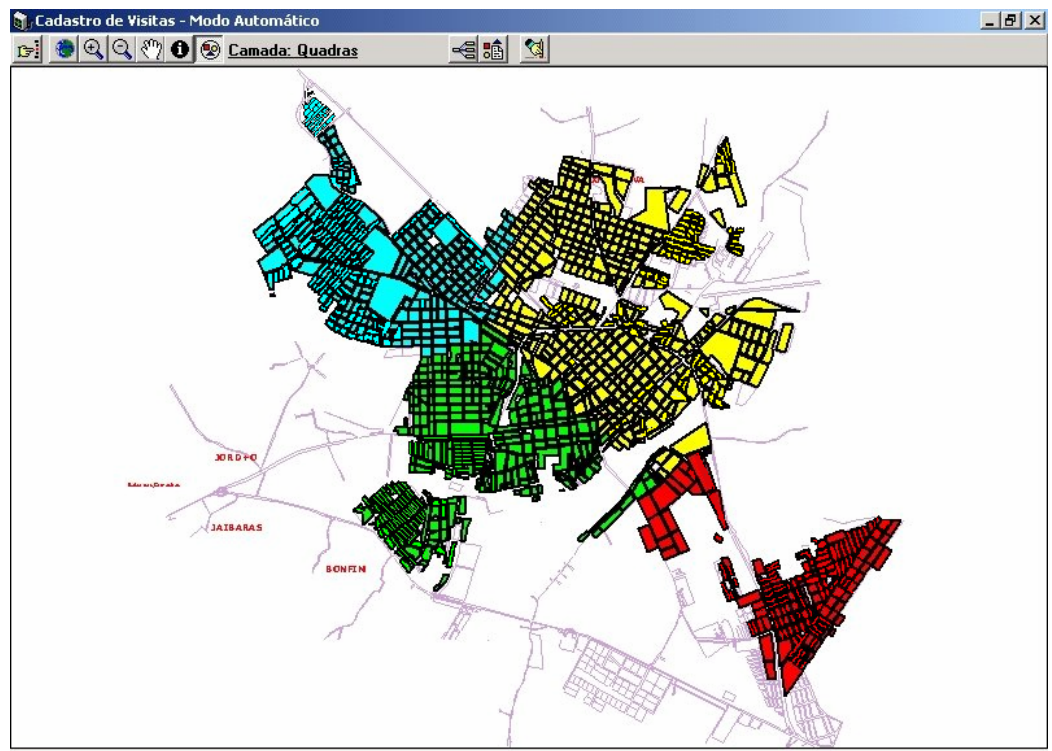

Figura 5 - Formação de clusters de quadras de imóveis de Sobral/CE, fornecida pela resolução do problema de Agrupamento Capacitado com Centro Geométrico.

Para representar o modelo, tem-se:

Conjuntos:

$I$ - é o conjunto dos imóveis, $\|\mathrm{I}\|=n$;

$J$ - é o conjunto de possíveis clusters, $1 \leq\|J\| \leq n$;

$F$ - é o custo fixo para abrir um cluster.

Parâmetros:

$\underline{Q}_{j}$ - é a capacidade mínima do cluster $j$;

$\bar{Q}_{j}$ - é a capacidade máxima do cluster $j$;

$a_{i}$ - é a posição do imóvel $i$ no espaço euclidiano $\mathfrak{R}^{2}$;

Variáveis:

$z_{j}= \begin{cases}1, & \text { se o cluster } j \text { é aberto; } \\ 0, & \text { caso contrário. }\end{cases}$

$y_{i j}= \begin{cases}1, & \text { se o imóvel } i \text { é atribuído ao cluster } j ; \\ 0, & \text { caso contrário. }\end{cases}$

$\bar{x}_{j}$ - é o centro geométrico do cluster $j$; 
Uma formulação genérica para o Modelo Generalizado do Problema de Agrupamento Capacitado com Centro Geométrico seria:

$$
\text { (g- PACCG) Minimizar }\left(\mathrm{F} \sum_{j \in J} z_{j}\right)+\sum_{j \in J} z_{j}\left(\sum_{i \in I}\left\|a_{i}-\overline{x_{j}}\right\|^{2} y_{i j}\right)
$$

tal que,

$$
\begin{aligned}
& \sum_{j \in J} y_{i j}=1, \quad \forall i \in I \\
& \sum_{i \in I} a_{i} y_{i j}=\bar{x}_{j}\left(\sum_{i \in I} y_{i j}\right), \quad \forall j \in J \\
& \underline{Q}_{j} z_{j} \leq \sum_{i \in I} y_{i j} \leq \bar{Q}_{j} z_{j}, \quad \forall j \in J \\
& \bar{x}_{j} \in \mathfrak{R}^{2}, z_{j}, y_{i j} \in\{0,1\}, \forall i \in I, \forall j \in J
\end{aligned}
$$

No modelo do Problema Genérico de Agrupamento Capacitado com Centro Geométrico ( $g$-PACCG) acima, a função objetivo busca minimizar o número de grupos de imóveis a serem visitados e a soma das dissimilaridades de cada um desses clusters, [5]. Um imóvel só pode ser atribuído a um único cluster, no conjunto de restrições [6]. Nas restrições [7], temos a garantia da localização do centro de cada cluster no seu centro geométrico. As restrições [8] consideram a manutenção da demanda de indivíduos limitada a capacidade de cada cluster particular, e as restrições [9] especificam as variáveis de decisão.

A formulação mostra o quão difícil é o problema. Esse pode ser reduzido a um problema equivalente NP-Completo, que é o próprio problema de Min-Sum Clustering, [GJ79].

Métodos de agrupamento restrito, que se ajustam a esse problema após algumas mudanças, foram desenvolvidos por Negreiros \& Palhano, os quais utilizam na sua fase inicial um método de agrupamento irrestrito. A qualidade das soluções desses procedimentos depende dessa etapa, conforme apontam os autores. Para consecução dessa fase inicial pode-se usar o método de clustering apresentado em 4.1, [NP 2006].

Para resolver o problema de divisão de cobertura territorial, inicialmente foi executado um método de clustering restrito genérico, para criação das áreas de cobertura das turmas de agentes (p.ex. áreas com 3024-3696 imóveis), e em seguida para cada área foram gerados os agrupamentos diários (18-22 imóveis), podendo o inverso também ser feito. Para cada grupo diário foi gerada então uma lista de visitação entre os imóveis do grupo a partir das quadras alocadas a cobrir, como será visto no modelo de escala de agentes.

\subsubsection{Divisão do Trabalho dos Agentes nas Áreas de Cobertura}

O interesse é distribuir os agentes por "macro-região" (ou bairro), de tal modo que a cobertura total da cidade esteja sendo explorada a cada dia, fornecendo subsidiariamente uma inferência de natureza amostral sobre toda a região. Ou seja, as amostras diárias idealmente deveriam apresentar um quadro sintético da cidade sobre os focos. Nesse caso, em princípio, os agentes devem estar o mais afastados entre si, pelo caráter de representatividade espacial, 
simultaneamente nos dias subseqüentes devem tomar imóveis os mais próximos dos visitados no dia anterior, pela continuidade do trabalho.

Assim, esse problema está relacionado a dois critérios simultâneos de otimização (afastamento entre agentes e similaridade dos grupos cobertos), e uma componente dinâmica de cobertura diária. O modelo esperado considera um processo de alocação dinâmica, cuja forma básica de formulação foi estudada por um número de pesquisadores, e reportados em recente survey sobre localização estratégica, [OD97].

Para ilustrar melhor como se processa isso, as Figuras 6(a) e (b) apresentam uma divisão do trabalho, imóvel a imóvel, dos agentes do controle focal, para uma área definida. $\mathrm{O}$ trabalho diário dos agentes que atuam nessa área deveria ser o mais disperso entre eles, ao mesmo tempo em que, no dia seguinte, deveria ser realizado em grupos de imóveis (18-22) que estão na vizinhança daqueles visitados no dia anterior por cada agente. Para se obter tal vizinhança, utilizamos o método de triangulação de Delaunay combinado a um processo de extensão de vizinhança entre imóveis, onde os centros dos grupos de imóveis diários seriam tomados como sendo aqueles de avaliação do deslocamento, [PS85].

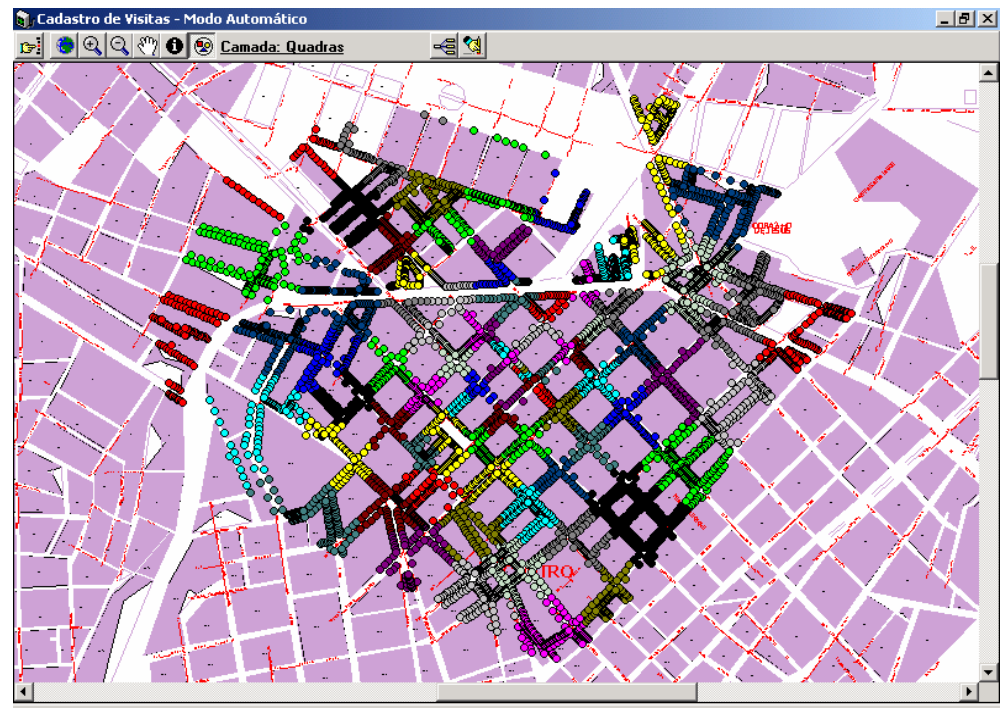

Figura 6(a) - Divisão das visitas de uma turma de agentes numa área definida para atendimento de uma turma de agentes - Visão Macro. 


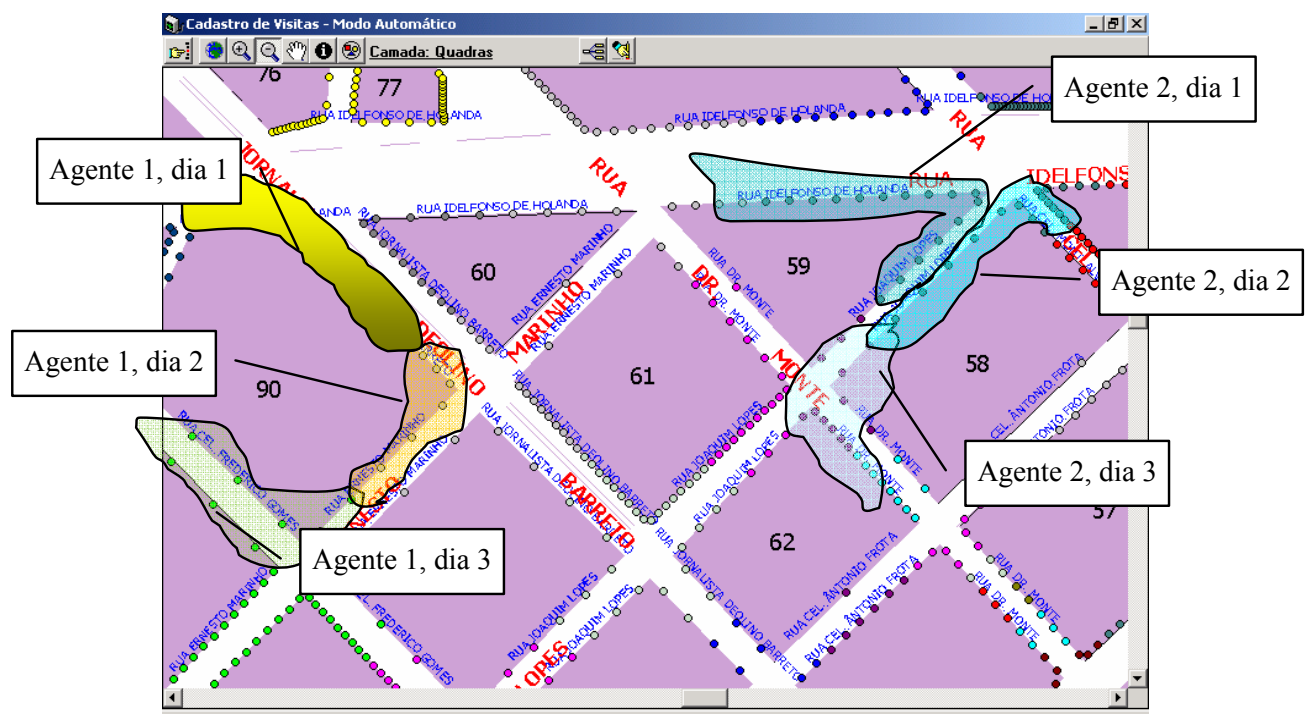

Figura 6(b) - Visualização pontual da cobertura dos agentes e das visitas de uma turma na área macro definida na Figura 6(a).

Esse problema, denominado de Problema de Designação de Cobertura de Agentes Sanitaristas (PDCAS), pode ser colocado sob a forma:

Conjuntos:

$C$ - é o conjunto dos Clusters (Áreas de cobertura);

$a_{c}$ - cada macro-região (cluster) $c$ tem um conjunto de $a_{c}$ sub-clusters;

$N(i)$ - são os sub-clusters vizinhos do sub-cluster $i$;

Parâmetros:

$H$ - é a duração em dias de um ciclo;

$d_{i j}$ - é a distância (euclidiana) entre os agentes $i$ e $j$;

$M$ - é um valor grande em relação a $d_{i j}$;

Variáveis:

$t_{k}$ - é a distância mínima entre dois agentes no dia $k$;

$x_{l j}^{k}=\left\{\begin{array}{l}1, \text { se o agente } l \text { visita o sub-cluster } j \text { no dia } k \\ 0, \text { caso contrário. }\end{array}\right.$ 
Modelo de Designação de Cobertura de Agentes Sanitaristas:

(PDCAS) Maximizar $\sum_{k=1}^{H} t_{k}$

Sujeito a,

$$
\begin{aligned}
& t_{k} \leq d_{i j}+M \max \left(1-x_{l i}^{k}, 1-x_{l^{\prime} j}^{k}\right), \forall k, \forall i, \forall j, \forall l, \forall l^{\prime} ; \\
& \sum_{l \in a_{c}} \sum_{k=1}^{H} x_{l j}^{k}=1, \forall j \in C, \forall c \in C \\
& \sum_{j \in C} x_{l j}^{k} \leq 1, \forall k, \forall l=1, \ldots, a_{c}, \forall c \in C \\
& x_{l j}^{k}+\sum_{j \notin N(i)} x_{l j}^{k+1} \leq 1, \forall k, \forall l, \forall j \\
& t_{k} \geq 0, \quad x_{l j}^{k} \in\{0,1\}, \forall k, \forall l, \forall j
\end{aligned}
$$

No modelo acima, a função objetivo busca maximizar a soma das distâncias mínimas de deslocamento entre dois dias consecutivos do período de cobertura realizados pelos agentes sanitaristas. As restrições [11] consideram $t_{k}$ como sendo a menor distância que separa dois sub-clusters (imóveis de um dia de visita) visitados. Nas restrições [12], cada sub-cluster de cada cluster tem que ser visitado por um agente do cluster. Em [13] temos as restrições que indicam que cada agente do cluster $c$ somente pode visitar um sub-cluster de $c$. As restrições [14] consideram que dentro de um período somente é permitida uma visita de sub-clusters vizinhos no dia subseqüente. As restrições [15] consideram as variáveis de decisão do modelo, correspondentes às de distâncias e às de alocação binária.

Outras funções objetivo podem ser consideradas, tais como:

$$
\text { (PDCAS-1) Maximizar } \sum_{k=1}^{H}\left(t_{k}\right)^{\frac{1}{2}}
$$

(PDCAS-2) Maximizar Min $t_{k}$

Esse modelo foi levado à Regional II de Fortaleza/CE. Devido aos dados disponíveis não incluírem as informações "imóvel a imóvel", e sim "quadra a quadra”, foi feita uma adaptação para a garantia de o agente do controle focal permanecer estável em um mesmo subgrupo ao longo de seu horizonte de cobertura no ciclo de trabalho. Devido a essa situação, o modelo foi resolvido em três etapas: definição das vizinhanças de quadra, agrupamento e roteamento dinâmico dos agentes entre quadras.

Na primeira etapa, foi construído o gráfico de vizinhança das quadras usando um método de triangulação de Delaunay, que, a partir dos centros de quadra, define uma triangulação mínima entre esses pontos que conecta os seus vizinhos. Uma vez que esse método não foi suficiente, haja vista a topologia dos polígonos das quadras, uma adaptação dos critérios de vizinhança da estrutura das quadras foi feita e assim corrigida a vizinhança global, Figura 7, [PS85].

Pesquisa Operacional, v.28, n.1, p.1-27, Janeiro a Abril de 2008 
Na segunda etapa, foi avaliada a possibilidade de gerar inicialmente percursos com agentes, usando heurísticas que retornariam naturalmente os subgrupos. As heurísticas atuaram sobre a vizinhança das quadras, considerando os tempos de permanência em cada quadra, com os dados reais de quantidade de imóveis que foram inseridos no sistema Gestor. Inicialmente foi deixada livre a possibilidade de percorrer as áreas, porém o resultado não foi dos melhores para cada um dos grupos de 10 bairros disponíveis para os testes. Por isso mesmo, essa configuração foi rejeitada pelo supervisor da Regional II de Fortaleza. Foi testada uma nova abordagem, com uma fase de agrupamento considerando as capacidades, onde foi conseguida uma melhor estrutura para a geração dos percursos que serão discutidos na fase de roteamento dos agentes do controle focal, Figura 8, [SERGHINE 2006].

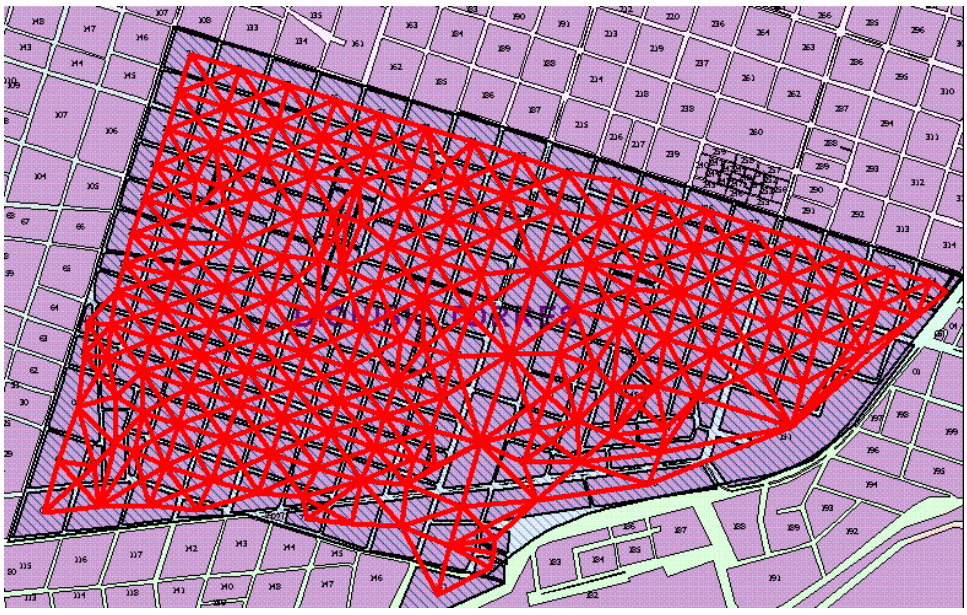

Figura 7 - Regiões de vizinhança das quadras do bairro Dionísio Torres/Fortaleza (Gestor).

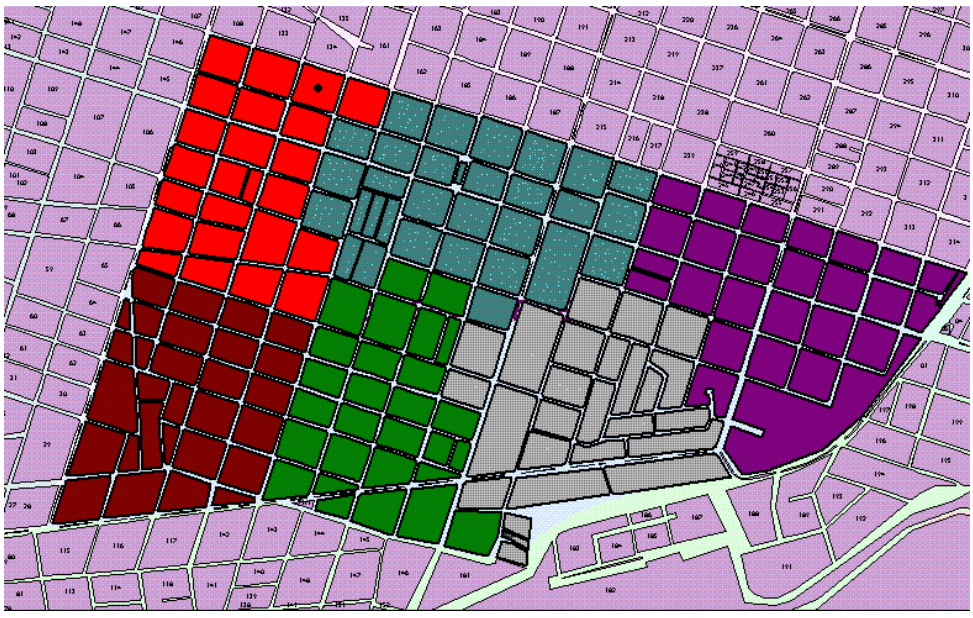

Figura 8 - Exemplo de agrupamento com capacidades de atendimento para o bairro de Dionísio Torres com 6 agentes. 


\subsection{O Planejamento de Veículos "Fumacês" (Tarefas de Cobertura Periódicas)}

O problema insere-se num planejamento dinâmico da cobertura das áreas de risco, a partir dos casos identificados e/ou notificados, ou a partir de um conhecimento estatístico do comportamento expansionista do mosquito na cidade. Em geral, essa metodologia é utilizada quando se está tratando do problema de divisão do serviço entre veículos "fumacês", que realizam a tarefa em períodos de surtos epidêmicos. Como os recursos de equipamento dessa natureza são pequenos, a necessidade desse planejamento é crucial nesse momento importante. Até mesmo porque, para cobrir regiões urbanas em metrópoles ou mesmo cidades de médio porte, são necessárias muitas áreas de cobertura, assim como muitos veículos para tratar o problema.

A fase de dimensionamento dos setores de atendimento, seja para os agentes, seja para os veículos "fumacês", é realizada anteriormente à fase de escalonamento, conforme proposto por Coutinho (2003), [EFC 2003]. Nela, garante-se que o serviço de atendimento é dimensionado para um determinado tempo ou carga total de serviço (número de quarteirões a serem atendidos por dia).

O problema de planejamento está entre os problemas de escalonamento de tarefas periódicas, onde se tem um conjunto de tarefas a serem realizadas em certas áreas definidas, em certos horários (no caso da dengue, para o "fumacê", das 5:00 às 7:00 e das 17:00 às 19:00, e para os agentes, diretamente nas residências e comércios, durante a manhã e a tarde) e numa dada periodicidade mínima e máxima de atendimento (intervalos entre dois atendimentos). $\mathrm{O}$ problema de escalonamento periódico de tarefas é NP-HARD, e tem merecido pouca atenção da literatura, [VLAM 1998], [BPN2001]. Para o caso específico, uma formulação matemática pode ser colocada, da seguinte forma:

\section{Premissas}

1. Um único veículo atende a uma única área num dia de serviço (1 veículo/ 1 área/ 1 dia);

2. Um veículo atende completamente uma região (várias áreas) em um dia;

3. Deseja-se realizar uma escala que minimize a frota utilizada, a qual deverá cobrir todas as áreas atendendo as necessidades de periodicidade mínima e máxima estipuladas.

Conjuntos:

$H$ - é horizonte de planejamento em dias corridos;

$A$ - conjunto das áreas a serem cobertas;

Parâmetros:

$L I(a)$ - limite inferior sobre o número de dias entre duas visitas na área $a$;

$L S(a)$ - limite superior sobre o número de dias entre duas visitas na área $a$;

Variáveis:

$$
\begin{aligned}
x_{i a}^{k} & = \begin{cases}1, & \text { se o veículo } i \text { visita a área } a \text { no dia } k ; \\
0, & \text { caso contrário. }\end{cases} \\
z_{a}^{k} & = \begin{cases}1, & \text { se a área } a \text { for visitada no dia } k ; \\
0, & \text { caso contrário. }\end{cases} \\
y_{i} & = \begin{cases}1, & \text { se o vé́culo } i \text { for usado } \\
0, & \text { caso contrário. }\end{cases}
\end{aligned}
$$

Pesquisa Operacional, v.28, n.1, p.1-27, Janeiro a Abril de 2008 
Um modelo de escala periódica pode ser colocado sob a forma:

$$
\begin{aligned}
& \text { (PEPVA) Minimizar }\left(\sum_{i=1}^{K} y_{i}\right) \\
& \sum_{i=1}^{L S(a)} z_{a}^{k} \geq 1, \quad \forall a ; \\
& z_{a}^{k}=\sum_{i=1}^{K} x_{i a}^{k}, \quad \forall a, \forall k \\
& z_{a}^{k} \leq \sum_{s=L I(a)}^{L S(a)} z_{a}^{k+s}, \quad \forall a, \forall k=1, \ldots, H-L S(a) \\
& \sum_{a=1}^{A} x_{i a}^{k} \leq y_{i}, \quad \forall i, \quad \forall k \\
& y_{i}, z_{a}^{k}, x_{i a}^{k} \in\{0,1\}, \quad \forall i, \forall a, \forall k
\end{aligned}
$$

No modelo acima de Escala Periódica de Veículos em Áreas (PEPVA), a função objetivo deseja minimizar o número de veículos da frota alocada no período, [18]. As restrições [19] consideram que cada área deve ser visitada nos primeiros LS(a) dias. As restrições [20] fazem uma ligação entre as variáveis $z$ e $x$. As restrições [21] consideram que se deve voltar em cada área, entre LI(a) e LS(a) dias depois de uma visita. As restrições [22] consideram que apenas um veículo visita no máximo uma área por dia. E por fim, as restrições [23] apresentam as variáveis de decisão do modelo de Escala Periódica. A Tabela 2 mostra uma situação hipotética do modelo, (a) informa a periodicidade (mínima e máxima) em dias para atender as diversas áreas, e (b) ilustra a solução da alocação conforme o dado plano de periodicidade.

Tabela 2 - Alocação ilustrativa de veículos V1 e V2 para as áreas 1 a 5.

(a)

\begin{tabular}{|c|c|c|}
\hline Área (zona) & $\mathbf{F}_{\min }\left(\mathbf{l}^{\mathbf{a}}\right)$ & $\mathbf{F}_{\mathbf{m a x}}\left(\mathbf{u}^{\mathbf{a}}\right)$ \\
\hline $\mathrm{A} 1$ & 2 & 3 \\
\hline $\mathrm{A} 2$ & 2 & 5 \\
\hline $\mathrm{A} 3$ & 1 & 3 \\
\hline $\mathrm{A} 4$ & 1 & 5 \\
\hline A5 & 3 & 5 \\
\hline
\end{tabular}

(b)

\begin{tabular}{|c|c|c|c|c|c|}
\hline Dia & Área 1 & Área 2 & Área 3 & Área 4 & Área 5 \\
\hline 1 & $\mathrm{~V} 1$ & & $\mathrm{~V} 2$ & & \\
\hline 2 & & $\mathrm{~V} 1$ & & $\mathrm{~V} 2$ & \\
\hline 3 & & & $\mathrm{~V} 1$ & & $\mathrm{~V} 2$ \\
\hline 4 & $\mathrm{~V} 1$ & & & $\mathrm{~V} 2$ & \\
\hline 5 & & $\mathrm{~V} 1$ & & & \\
\hline 6 & & & $\mathrm{~V} 1$ & $\mathrm{~V} 2$ & \\
\hline 7 & $\mathrm{~V} 1$ & & & & $\mathrm{~V} 2$ \\
\hline 8 & & $\mathrm{~V} 1$ & $\mathrm{~V} 2$ & & \\
\hline
\end{tabular}




\subsection{Problemas de Roteamento}

\subsubsection{Agentes Sanitaristas}

\section{Percurso dos Agentes do Controle Focal}

Mantendo a idéia geral do processo de cobertura do modelo PDCAS, o sistema Gestor calcula os percursos dos agentes mantendo-os o mais afastado possível ao longo do período, com a intenção de dar aos gestores uma noção correta do que está acontecendo na região em termos de evolução da doença.

Um novo problema de combinatória nos surgiu, que denominamos de Problema do Caminho do Caixeiro Viajante sobre um Grafo Dinâmico. Nesse problema, a cada cidade (quadra) visitada, a menos da origem, as conexões das cidades (quadras) vizinhas após a visita são removidas. Assim o caixeiro tem que fazer um percurso que considera a vizinhança e a manutenção de um trajeto mínimo entre origem, e um destino nessas condições. Na nossa tentativa, somente abordamos inicialmente o percurso com a possibilidade de acontecer fora da vizinhança da quadra, usando a função objetivo [10] do modelo PDCAS. A Figura 9 apresenta uma avaliação de percurso no bairro Dionísio Torres para a situação real, [SERGHINE 2006].

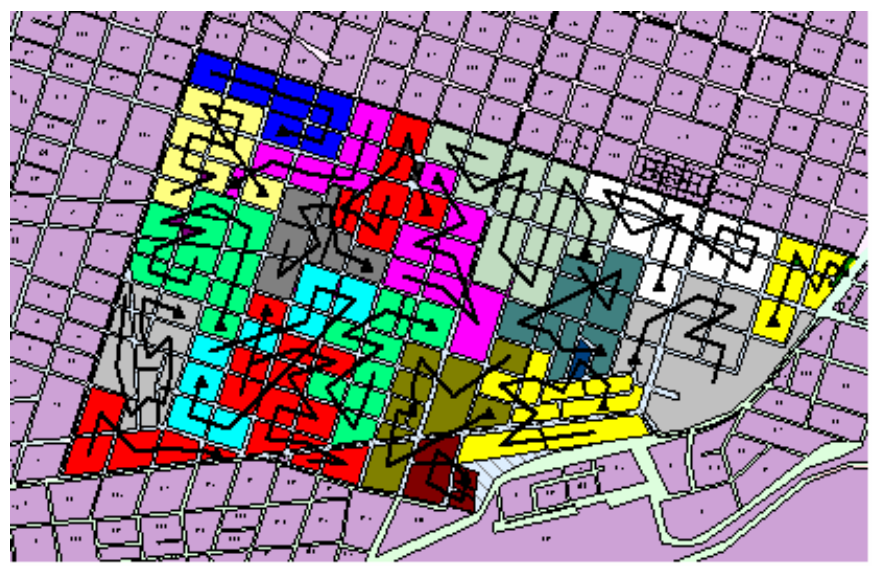

Figura 9 - Exemplo de avaliação do método de percurso dinâmico no bairro Dionísio Torres/Fortaleza-CE, 20 grupos de agentes em 12 dias úteis de trabalho.

\section{Percurso dos Agentes do Controle de PS's}

Já para os agentes dos PS's, avaliado em Fortaleza, o percurso acontece de forma bastante peculiar, ou seja, um agente atribuído a um conjunto de bairros deve visitar seus imóveis de modo que visite o conjunto de imóveis de um mesmo bairro por vez. Chama-se então de problema do Caixeiro Viajante em Grupos (Clustered Traveling Salesman Problem), e foi resolvido com pequenas transformações sobre o grafo euclidiano formado pelos pontos entre os imóveis alocados ao mesmo agente, [PRUNNEN 2002].

O problema desse percurso foi resolvido usando algoritmos meta-heurísticos de caminho hamiltoniano entre quadras mais distantes e heurísticas de melhorias, numa visão temática de 
deslocamento, conforme as Figuras 10 e 11. Dessa forma, hoje se garante que um novo bairro somente será visitado por um agente se tiver completado o anterior. Assim, fica como tarefa do supervisor alocar e acompanhar os agentes bairro a bairro, garantindo a simultaneidade das visitas no mesmo bairro pelos agentes, [PD 2002].

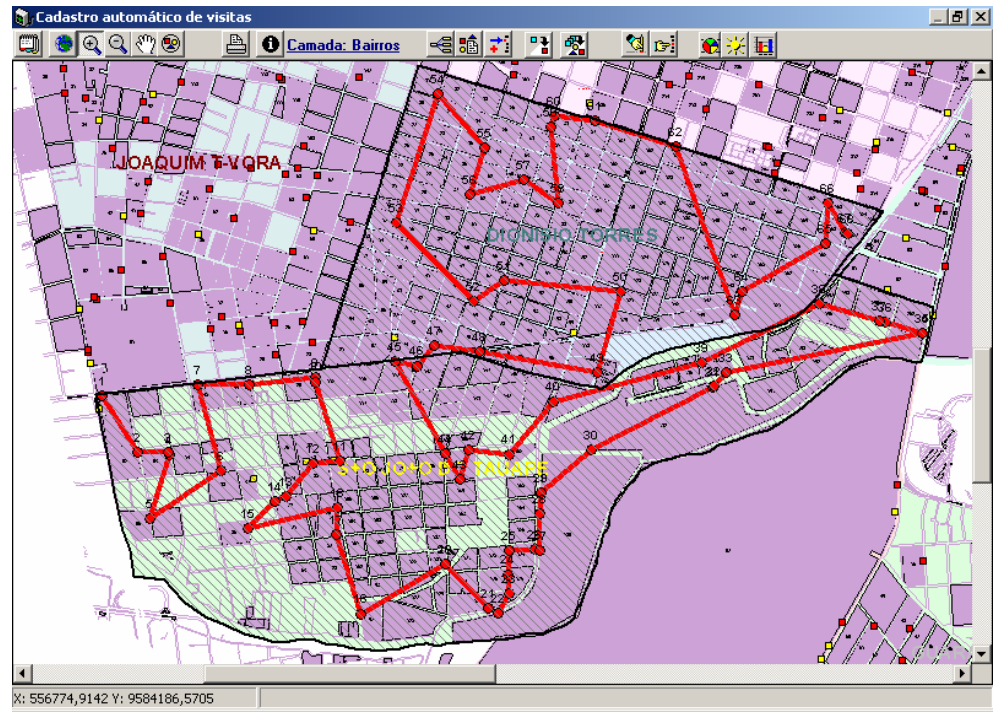

Figura 10 - Itinerário de visita entre bairros, respeitando a seqüência de visita entre bairros e tomando os mais distantes entre o bairro origem e o destino (SJ do Tauape e Dionísio Torres).

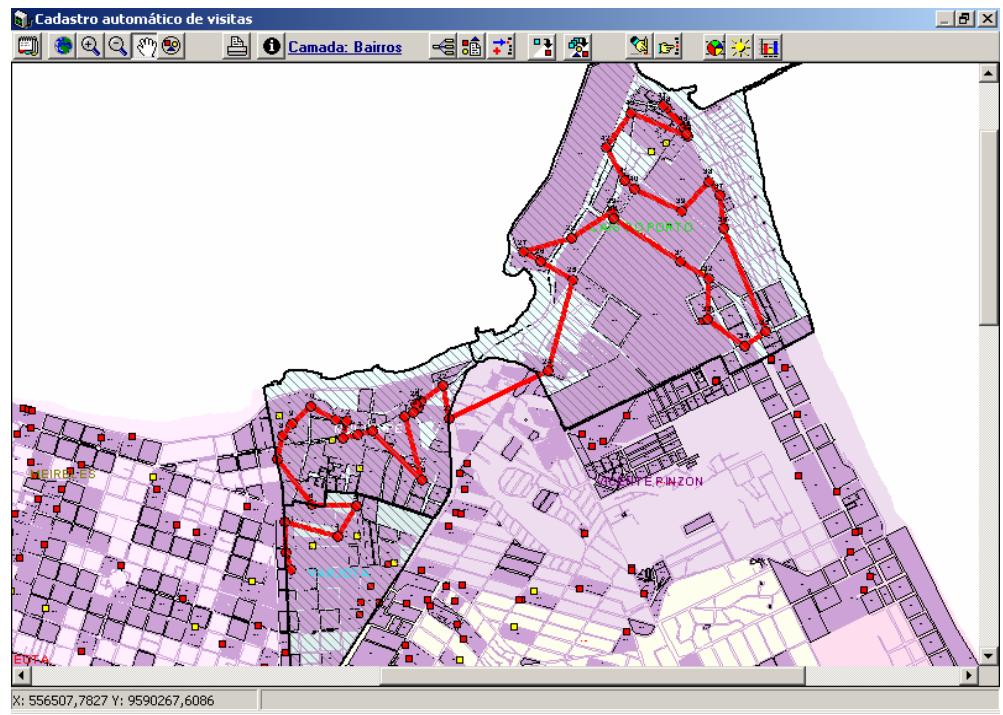

Figura 11 - Outro itinerário entre PS's dos bairros Varjota, Mucuripe e Vicente Pizón. 
No início do trabalho de aplicação da metodologia, os tempos de visita por imóvel fornecidos pelos agentes eram muito diferentes dos realmente executados, o que levou a fazermos um relatório gerencial e um acompanhamento via palms para os supervisores que tiveram, a partir daí, uma visão mais aproximada ou realista do que estava acontecendo em termos de visita imóvel a imóvel. Isto na prática refletiu na extinção de muitos PS's e criação de novos (devido à baixíssima incidência verificada pelo acompanhamento via Webdengue e anotação com palms), e aumentou-se o controle efetivo sobre os imóveis na atividade de controle nos PS's. Além disto, houve uma redução acentuada no número de agentes sanitaristas alocados nessa atividade (de 13 para 11 agentes), haja vista a redistribuição e otimização das tarefas. Em 2006 o número de agentes nos PS's foi reduzido para 9 na Regional II, significando uma economia de $25 \%$ no contingente, que foram realocados para o serviço focal.

\subsubsection{Veículos "Fumacês"}

Uma vez definidas as áreas de atendimento e procedida a escala de serviço dos agentes, existe a fase de roteirização do serviço dos veículos "fumacês", de modo a facilitar o trabalho do gestor na tarefa de atendimento à população em situações epidêmicas. Nessa fase, utilizam-se modelos baseados no problema do Carteiro Rural (PCR), onde se garante que o serviço será realizado com a passagem do "fumacê" por todos os quarteirões onde seu serviço foi requisitado, com o menor custo total no trajeto, [EGL95], [NEG 96], [EFC 2003].

Esse problema de fato relaciona-se à minimização do gasto com inseticidas e tempo de percurso, além da garantia quanto à cobertura integral das áreas afetadas, uma vez que os veículos "fumacês" acionam as bombas de pulverização ao penetrarem nas áreas de serviço, desligando-as somente quando a tarefa em cada setor for concluída. Obtém-se a redução dos gastos a partir da melhor elaboração dos roteiros, e, ademais, os setores definidos terão atendimento mais rápido, [NEG 96].

Uma vez que o percurso do veículo está limitado, além da área especifica, à quantidade de inseticida presente no ambiente, temos o problema de Percurso em Arcos Capacitados (PPAC) proposto inicialmente por Golden \& Wong, [GW 81]. Deve-se considerar, ademais, a orientação específica na malha viária para a passagem do veículo "fumacê", tendo em vista que o bico pulverizador do inseticida é fixo e se situa do lado direito, [BBLPR-C 2007].

As Figuras 12 a 16, a seguir, ilustram algumas das visualizações das saídas dos resultados deste modelo, para organizar de forma adequada a logística dos "fumacês" na prevenção a dengue.

Os modelos aqui colocados não foram ainda utilizados, porém fazem parte do arsenal sistêmico do framework computacional, através de trabalhos desenvolvidos anteriormente para a coleta de lixo, [NEG96], [XNES2007].

Na Figura 12 vemos inicialmente o processo de confecção das regiões de atendimento; em seguida, na Figura 13, um processo de divisão da região 02 em 4 sub-clusters, com capacidade limitada a dois mil litros de inseticida por sub-cluster. Na Figura 14, os cronogramas de atendimento da área presumem um programa de trabalho fixo, em dias estabelecidos, com periodicidade máxima de atendimento prevista dentro do ciclo do mosquito. A Figura 15 mostra um roteiro temático de custo mínimo de atendimento da área,

Pesquisa Operacional, v.28, n.1, p.1-27, Janeiro a Abril de 2008 
onde visualizamos um multigrafo resultante, com os percursos possíveis a serem feitos pelo veículo "fumacê" ou pelo agente de saúde. Por fim, na Figura 16, temos o problema de movimentação do veículo "fumacê", considerando que vai sempre estar com o bico pulverizador direcionado à frente das residências, [NCPO 2001].

Em suma e em essência, a forte integração entre os problemas de cobertura dos agentes sanitaristas e veículos "fumacês" nas regiões infestadas, e sua escala no período de execução do serviço, requer estudos específicos de efetividade de métodos de otimização para validar se são realmente capazes de atender aos anseios do gestor no sentido de otimizar os seus custos, atendendo de forma racional às suas necessidades. As metodologias vêm se constituindo capazes de abordar o problema de prevenção e combate à dengue, podendo prover informações com altos graus de confiabilidade e de velocidade para os gestores dos centros de Zoonoses da Regional II de Fortaleza e Sobral, [NEG 96], [NPCO2001], [EFC 2003], [NP 2006].

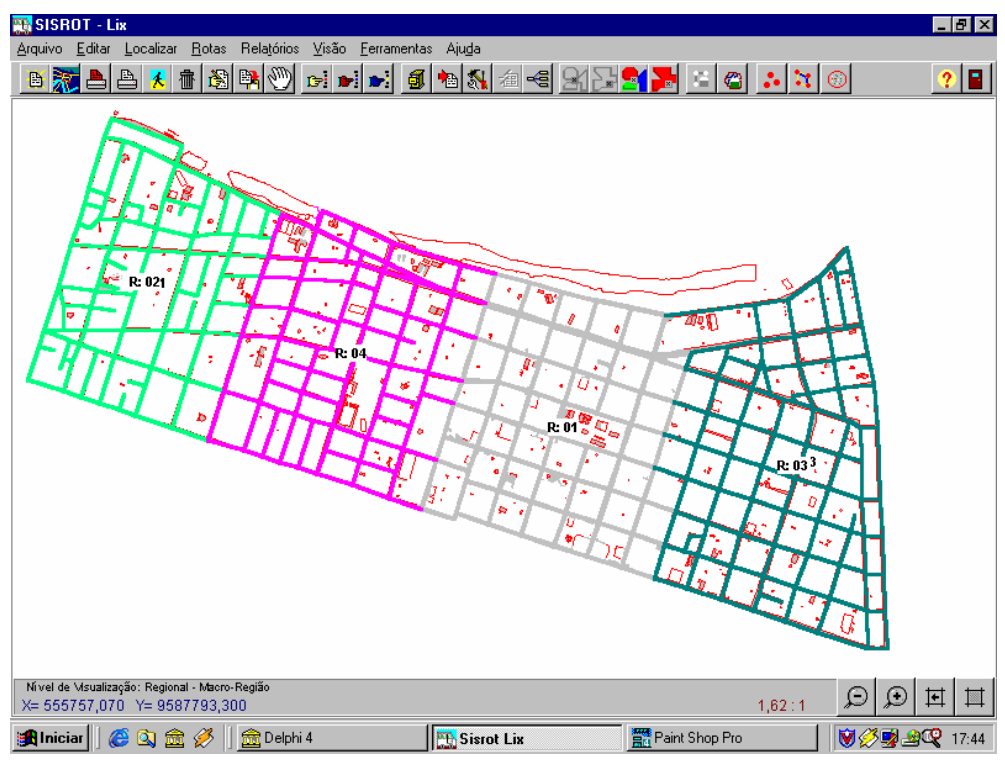

Figura 12 - Divisão de áreas de atendimento conforme a capacidade de serviço do veículo "fumacê". 


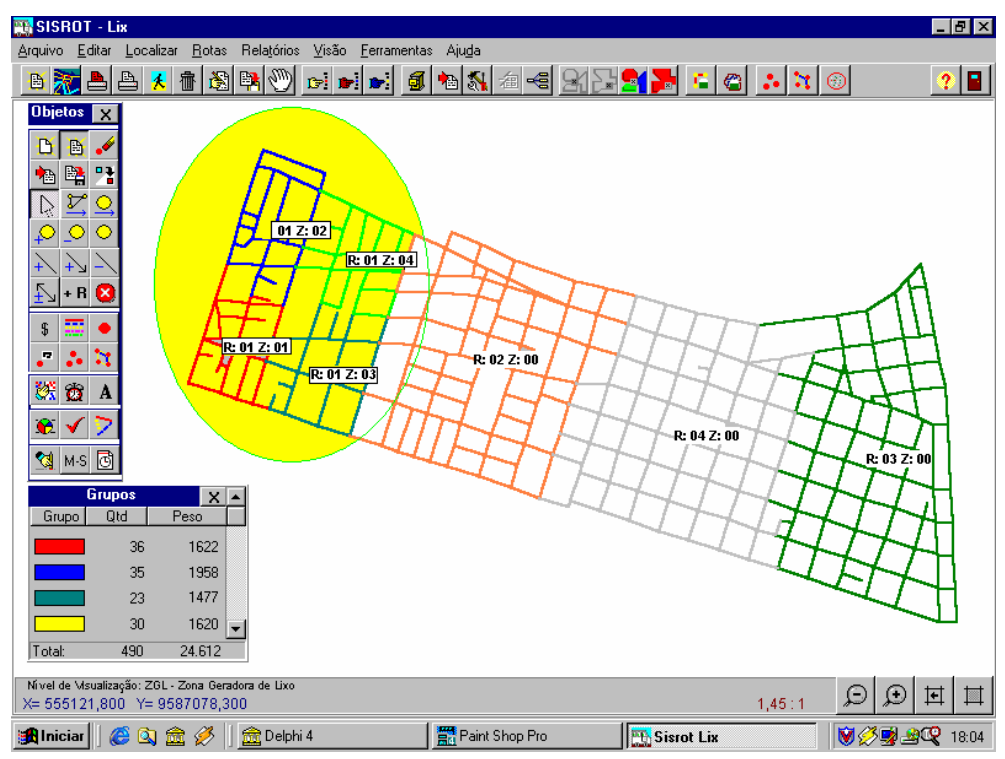

Figura 13 - Nova divisão conforme os dias numa única área.

\begin{tabular}{|c|c|c|c|}
\hline \multicolumn{3}{|c|}{ Calendário de Viagens } & 01/11/2001 18:18:54 \\
\hline $\begin{array}{c}\text { Área : R: } 01 \\
\text { Data: }\end{array}$ & Capacidade da z ona : 4689 & Caminnao & Quantidade de c aminhỗes : 47 \\
\hline 01/10/2001 & Segunda-feira & 1 & \\
\hline 04/10/2001 & Quinta-feira & 2 & \\
\hline 07/10/2001 & Domingo & 3 & \\
\hline 10/10/2001 & Quarta-feira & 4 & \\
\hline 13/10/2001 & Sábado & 5 & \\
\hline $16 / 10 / 2001$ & Terç afeira & 6 & \\
\hline 19/10/2001 & Sextafeira & 7 & \\
\hline $22 / 10 / 2001$ & Segunda-feira & 8 & \\
\hline 25/10/2001 & Quinta-feira & 9 & \\
\hline $28 / 10 / 2001$ & Domingo & 10 & \\
\hline $31 / 10 / 2001$ & Quarta-feira & 11 & \\
\hline Total de viagen & $: 11$ & & \\
\hline
\end{tabular}

Figura 14 - Calendário de serviço numa dada área.

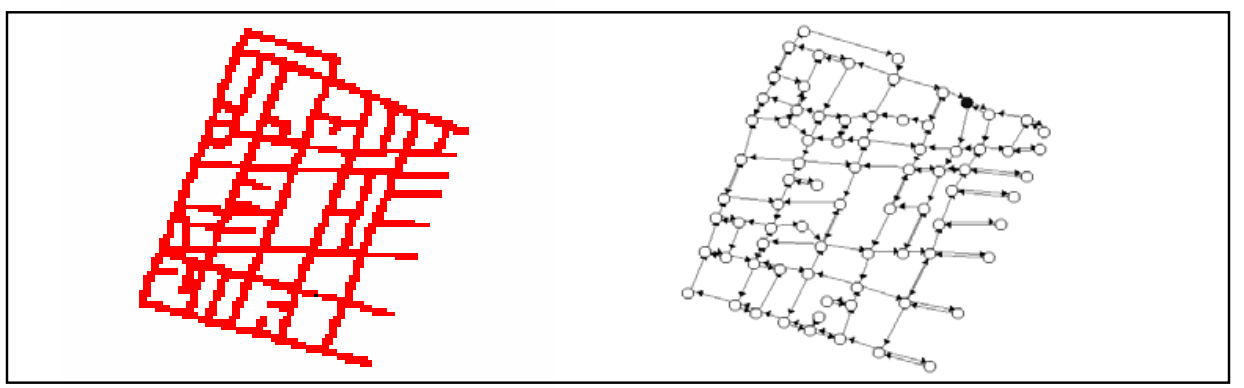

Figura 15 - Área de serviço e percurso ótimo correspondente. 


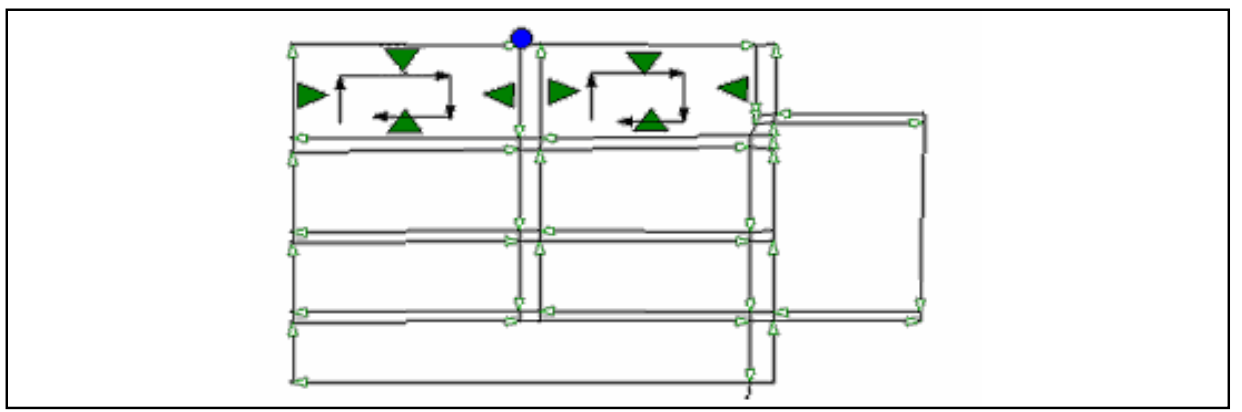

Figura 16 - Visão do grafo de orientação do percurso do veículo "fumacê" em uma área de uma cidade, onde é a posição do bico do pulverizador sempre voltado para dentro dos quarteirões representa uma restrição adicional.

\section{Conclusões}

Este trabalho descreve, em linhas gerais, a problemática da dengue nas regiões tropicais do mundo, destacando a preocupação da Organização Mundial de Saúde em tornar acessível, aos pesquisadores e aos gestores de saúde pública, as peculiaridades dessa doença, com o objetivo de se obter melhores e mais efetivos métodos de combate à mesma.

Essa problemática é particularmente relevante no Brasil, em particular, onde a ocorrência de grandes variações existentes nos números de casos de dengue notificados nos últimos anos é alarmante.

É apresentado um framework (arcabouço) computacional para subsidiar as atividades de prevenção e de controle da dengue. Ademais, são descritas situações operacionais práticas relacionadas à logística de prevenção e de combate à dengue, que configuram em problemas a serem equacionados. Nesse sentido, é proposto um conjunto de modelos matemáticos para o controle logístico das visitas dos agentes sanitaristas e dos veículos "fumacês". Alguns desses modelos já estão incorporados ao framework computacional desenvolvido. Grande parte dos modelos foi testada no dia a dia do controle da dengue assim como o próprio framework na cidade de Fortaleza, e parcialmente na cidade de Sobral/CE.

A complexidade dos problemas envolvidos, todos NP-Árduos, carece inexoravelmente do uso das ferramentas estado-da-arte de Otimização e obviamente da Pesquisa Operacional, para se encontrar soluções adequadas para esses problemas. Os modelos aqui reportados vêm sendo resolvidos através de metodologias aproximativas, metaheurísticas e heurísticas, os quais vêm atendendo às necessidades do gestor em tempo hábil, na designação dos serviços de prevenção e de combate à dengue.

\section{Agradecimentos}

Agradecemos ao Programa CAPES/COFECUB projeto 0476/04, CNPq pelo projeto PQ 202457 (pós-doutorado), CAPES/COFECUB através do projeto 0467/04, e programa ALFAEUROPEAID através do projeto ALFA II-0457-FA-FCD-F1-FC, FUNCAP-FINEP/CE Empresas Competitivas, CNPq-RHAE Inovação projeto 505594/2004-8, e à GRAPHVS Ltda, pelo apoio financeiro ao projeto. 
Agradecemos à Secretaria de Desenvolvimento Social e Saúde de Sobral, à Prefeitura Municipal de Sobral e ao Centro de Zoonoses de Sobral pelo apoio financeiro a este projeto. Aos supervisores do Centro de Zoonoses de Sobral, Raimundo Neto, e da Regional II/SMSPMF de Fortaleza, Carlos Alberto dos Santos Barbosa.

Nosso agradecimento à equipe de desenvolvimento de sistemas da GRAPHVS e UECE LCC: André Silva, Augusto Wagner Palhano, Albert Einstein Muritiba, Alfredo Thomaz, Ana Júlia Pessoa, Débora Lacerda, Érika de Sousa, Eugênio Emílio, Gustavo Sikora, Guy Barroso, Igor Ribeiro, Ingrid Teles, João Frederico, José Ernane Barbosa, José Ulisses, Najoua Serghine, Raphaele Pinheiro, Pedro Coutinho Filho, Rodrigo Cubas Ley, Ronaldo Virgínio e Wiler Coelho Jr, pelo compromisso em tornar este trabalho uma realidade.

Agradecimento especial ao Secretário Municipal (em ambas as cidades) Doutor Luiz Odorico Monteiro de Andrade por seu envolvimento e apoio incondicional a este projeto, em Fortaleza e em Sobral, Ceará.

\section{Referências Bibliográficas}

[BPN2001] Baptiste, P.; Le Pape, C. \& Nuijten, W. (2001). Constraint-Based Scheduling: Applying Constraint Programming to Scheduling Problems. Kluwer Academic Publishers.

[BYG 2002] Barbazan, P.; Yoksan, S. \& Gonzalez, J.P. (2002). Dengue Hemorrhagic Fever Epidemiology in Thailand: Description and Forecasting of Epidemics. Microbes and Infection, 4(7), 699-705.

[BLL 2003] Blais, M.; Lapierre, S.D. \& Laporte, G. (2003). Solving a home-care districting problem in an urban setting. Journal of the Operations Research Society, 54, 1141-1147.

[BBLP 2006] Belenguer, J-M.; Benavent, E.; Lacomme, P. \& Prins, C. (2006). Lower and upper-bounds for the mixed capacitated arc routing problem. Computers \& Operations Research, 33, 3363-3383.

[BLR 1981] Bourjolly, J-M.; Laporte, G. \& Rousseau, J-M. (1981). Découpage electoral automatisé: application à I'Île de Montreal. INFOR, 19, 113-124.

[BEL 2003] Bozkaya, B.; Erkut, E. \& Laporte, G. (2003). A tabu search heuristic and adaptative memory procedure for political districting. European Journal of Operations Research, 144, 12-26.

[CIVES 2002] CIVES - Martins, F.S.V. \& Castiñeiras, T.M.P.P. (2002). Dengue. www.cives.ufrj.br.

[CSMEBN 97] Cardoso Junior, R.P.; Scandar, S.A.S.; Mello, N.S.; Ernandes, S.; Botti, M. \& Nascimento, E.M.M. (1997). Detecção de Aedes Aegypti e Aedes Albopictus, Na Zona Urbana do Município de Catanduva-SP, Após Controle de Epidemia de Dengue. Rev. Soc. Bras. Med. Trop., 30(1), Uberaba, Jan./Fev. 1997.

[EFC 2003] Coutinho, E.F. (2003). Algoritmos de escala e roteamento de veículos para aplicação em serviços sistemáticos de regiões urbanas. Dissertação de Mestrado (MPCOMP-UECE/CEFET-CE), Jul./2004.

[EGL95] Eiselt, H.A.; Gendreau, M. \& Laporte, G. (1995). Arc Routing Problems, Part II: The Rural Postman Problem. Operations Research, 43(3), 399-414.

Pesquisa Operacional, v.28, n.1, p.1-27, Janeiro a Abril de 2008 
[EL 2001] Everitt, B.S.; Landau, S. \& Leese, M. (2001). Cluster Analysis. $4^{\text {th }}$ Ed. Arnold, Ed. and Oxford University Press.

[FN71] Fisher, L. \& van Ness, J.W. (1971). Admissible clustering procedures. Biometrika, 58, 91-104.

[GJ79] Garey, M.R. \& Jonhson, D.S. (1979). Computers and Intractability: A guide top the theory of the NP-Completeness. Ed. Freeman, San Francisco.

[GN70] Garfinkel, R.S. \& Nemhauser, G.L. (1970). Optimal political districting by implicit enumeration technics. Management Science, 16, 495-508.

[GW81] Golden, B.L. \& Wong, R.T. (1981). Capacitated Arc Routing Problems. Networks, 11, 305-315.

[HART1975] Hartigan, J. (1975). Clustering algorithms. Wiley Interscience, New York.

[HOOK2000] Hooker, J. (2000). Logic Based Methods for Optimization: Combining Optimization and Constraint Satisfaction. Wiley-Interscience Series in Discrete Mathematics and Optimization.

[HM 2001] Hansen, P. \& Mladenovic, N. (2001). J-Means: A New Local Search Heuristic for Minimum Sum-of-Squares Clustering. Pattern Recognition, 34(2), 405-413.

[KR90] Kaufmann L. \& Rousseauw, P.J. (1990). Finding groups in data: an introduction to cluster analysis. John Wiley \& Sons, New York.

[KEATING 2001] Keating, J. (2001). An Investigation into the Cyclical Incidence of Dengue Fever. Social Science \& Medicine, 53, 1587-1597.

[MJN 1998] Mehrotra, A.; Johnson, E.L. \& Nemhauser, G.L. (1998). An optimization based heuristic for political districting. Management Science, 44, 1100-1114.

[MS98] Marriott, K. \& Stuckey, P. (1998). Programming with Constraints: An Introduction. The MIT Press.

[NEG 96] Negreiros Gomes, M.J. (1996). Contribuições para Otimização em Grafos e Problemas de Percursos de Veículos: Sistema SisGRAFO. D.Sc. Thesis, UFRJ-COPPE, Eng. Sistemas e Computação.

[NP 2006] Negreiros Gomes, M.J. \& Palhano, A.W.C. (2004). The Capacitated Centred Clustering Problem. Computers \& Operations Research, 33, 1639-1663.

[NLXMXM 2006] Negreiros, M.J.; Lima, J.W.O.; Xavier, A.E.; Maculan, N.; Xavier, A.F.S. \& Michelon, P. (2006). The Prevention and Combat of the Dengue Disease by a Computational DSS WEB Based System. Application Results to Fortaleza and Sobral/CE - Brazil. EURONEWSLETTER\#9, Electronic Publication on www.euro-online.org, December 10, 2006.

[NCPO 2001] Negreiros Gomes, M.J.; Coutinho, E.F.; Palhano, A.W.C. \& Oliveira Filho, J.G.B. (2001). Agrupamento Capacitado Espacial e Escalonamento de Áreas de Serviço Sistemático através do Sistema SisRot LIX. XXXIII SBPO'2001 - Campos do Jordão/SP, Anais (Resume).

[OD 97] Owen, S.H. \& Drezner, Z. (1998). Strategic Facility location: A Review. European Journal of Operational Research, 111, 423-447.

[OSI 97] Okanuraki; Sornami \& Idartna (1997). The Cost of DHF in Thailand. South-East Asian Journal of Tropical Medicine and Public Health, 28(4), 711-717. 
[PRUNNEN 2002] Prunnen, A.P. (2002). The traveling salesman problem: Applications, formulations and variations. In: Combinatorial Optimization, The Traveling Salesman Problem and Its Variations [edited by Gregory Gutin and Abraham P. Punnen], Kluwer Academic Press.

[PD 2002] Combinatorial Optimization, The Traveling Salesman Problem and Its Variations [edited by Gregory Gutin and Abraham P. Punnen], Kluwer Academic Press.

[PS85] Preparata, F.P. \& Shamos, M.I. (1985). Computational Geometry: An Introduction. Springer-Verlag Ed.

[SERGHINE 2006] Serghine, Najoua (2006). Système de Prévention et de Combat de la Dengue à Fortaleza - Brésil: Planification d'emploi du temps d'agent sanitaires. MSc Dissertation, Universitè de Avignon, IMOD Master 2.

[SPATH85] Späth, H. (1985). Cluster Dissection and Analysis (Theory, Fortran Programs, Examples). Ellis Horwood, Chichester.

[TK 2003] Theodoridis, S. \& Koutroumbas, K. (2003). Pattern Recognition. $2^{\text {nd }}$ Ed. Elsevier Academic Press.

[TDR2004] Tropical Disease Research Center - WHO - http://www.who.int/tdr/index.html.

[VLAM 98] Verhaegh, W.F.J.; Lippens, P.E.R.; Aarts, E.R.L.; van Meerbergen, J.L. \& van der Werf, A. (1998). The Complexity of Multidimentional Periodic Scheduling. Discrete Applied Mathematics, 89, 213-242.

[WHO1999] World Health Organization (WHO) (1998-1999). The world Health Report. Geneva, 1999.

[XNMM05] Xavier, A.E.; Negreiros Gomes, M.J.; Maculan, N. \& Michelon, P. (2005). The Use of the Hyperbolic Smoothing Clustering Method for Planning the Tasks of Sanitary Agents in Combating Dengue. IFORS 2005 - Hawaii.

[ZHD 2007] Zhong, H.; Hall, R.W. \& Dessouky, M. (2007). Territory Planning and Vehicle Dispatching with Driver Learning. Transportation Science, 41(1), 74-89. 